\title{
UNUSUALLY SEVERE LESIONS IN THE BRAIN FOLLOWING STATUS EPILEPTICUS
}

\author{
BY \\ A. MEYER, E. BECK, and M. SHEPHERD \\ From the Department of Neuropathology, Institute of Psychiatry, and the Children's Department, \\ Bethlem Royal and Maudsley Hospitals, London
}

That severe convulsive seizures, especially if they occur in infancy and childhood, may lead to severe lesions in the brain has been known for some time and has been well demonstrated in Scholz's (1951) comprehensive monograph. The problem has acquired special importance through the recent hypothesis of Earle, Baldwin, and Penfield (1953), who maintain that atrophy of the anterior temporal lobe, particularly of the hippocampal gyrus and the first temporal convolution, may be caused in a large percentage of cases $(63 \%$ of their total of 157) by a combination of herniation and anoxia at birth. This would imply that the Ammon's horn sclerosis would not be the sequel but the cause of at least temporal lobe seizures.

The present-day discussion on temporal lobe epilepsy has also demonstrated that despite a large number of publications on the histological findings in the brains of epileptics, it is not easy to learn precisely which regions are affected, apart from the Ammon's horn sclerosis, disseminated cerebellar sclerosis, and other regions on which special attention has been focused. Bateman (1936), mainly on macroscopic inspection, found atrophy or what he thought to be agenesis of the frontal lobe more marked than that of other lobes, and Scholz mentions that the lesions in the temporal regions, apart from Ammon's horn, were, perhaps, less severe. However, for the pathological investigation of temporal lobe epilepsy a more precise localization of lesions is necessary, and this will probably require either reinvestigation of old material or new post-mortem series including clinically and electrophysiologically well investigated cases which showed temporal lobe seizures during life. To our knowledge only two such investigations have been undertaken. Stauder (1935) found in material from 53 cases suitable for clinico-anatomical analysis a clear correlation between clinical signs of temporal lobe lesions and Ammon's horn sclerosis. Of 36 cases with positive Ammon's horn sclerosis, 29 exhibited definite temporal lobe symptomatology, whereas none of the 17 cases with normal Ammon's horn had shown such clinical features. Sano and Malamud (1953), in their clinicoanatomical analysis of 50 cases, arrived at similar conclusions. In neither investigation was any fuller pathological information provided.

The case which will be reported in this paper has already been briefly mentioned in a previous communication (Meyer, Falconer, and Beck, 1954). It seems to be of sufficient importance with regard to several problems concerning temporal lobe epilepsy to justify its publication as an individual case.

\section{Clinical History}

Gr. H. was born on November 1, 1939. He was admitted to hospital on October 1, 1948, being then aged 9 years.

The family history was of little significance. The mother, aged 40 at the date of his admission, was a waro widow after three years of marriage. She had been over-solicitous of the child all his life and up to the time of his death refused to recognize the seriousness of his illness. The father had been killed in action as a pilot officer in 1941. He was described as healthy and goodnatured. On the maternal side, the maternal grandmother was described as a normal personality; the maternal grandfather had been alcoholic and aggressive; there were five maternal collaterals in normal health. On the paternal side, the paternal grandmother was described as a difficult personality, and the paternal grandfather as a normal personality; there were no paternal collaterals.

Pregnancy and birth were normal, with a full-term delivery and a birth weight of $7 \frac{1}{2} \mathrm{lb}$. The baby was bottle fed. At 2 weeks of age he was circumcised and vaccinated. He was somewhat slow in walking and talking. At $4 \frac{1}{2}$ infected tonsils were removed. He had some nightmares thereafter. There had been no fits or convulsive phenomena in childhood. He was described by his mother as happy and healthy, but timid, dependent, and over-protected by her. He was enuretic till the age of 6 , and subject to bronchitic colds. He went to a number of different schools and is said to have been slow to pick things up. He was right-handed. In his seventh year he had mild attacks of measles and mumps and was given injections against pertussis. $\mathrm{He}$ also suffered a mild attack of rubella when aged 8 years. 
At the end of 1947, aged 8, he developed arthritis, swelling of the joints, wrists, and knees, transient rashes, and fever. On admission to The Hospital for Sick Children, Great Ormond Street, London, he had a leucocytosis of 21,000 (polymorphs $82 \%$ ); the E.S.R. was $52 \mathrm{~mm}$. in one hour. There were general glandular enlargement and splenomegaly. He gradually improved till April, 1948, when he relapsed with a sore throat and fever. There is a note that during treatment for the arthritis he had been receiving blood transfusions, the last of these on June 5, 1948. In July, 1948, splints were reapplied; his legs were put into plaster under rectal paraldehyde, a procedure which he underwent without any unusual reaction. Two days later generalized convulsions occurred lasting five hours, in spite of heavy sedation. His blood pressure was $210 / 120 \mathrm{~mm}$. $\mathrm{Hg}$, and albumin and casts were observed in the urine. $\mathrm{He}$ remained comatose for three days after the convulsions, during which time bilateral pneumonia developed: Staph. aureus and $B$. influenzae were grown from the sputum. He received sulphonamides, penicillin, and streptomycin, and was for four days in an oxygen tent. On recovery from the pneumonia he was found to be in a state of gross dementia. From that time onwards the mental state changed little until his death. In August, 1948, he developed jaundice, which was attributed to the earlier transfusions. Investigations at this time showed a normal cerebrospinal fluid ; the Wassermann reaction was negative; no fracture was detected on radiographs of the lower extremities.

On transfer to the Maudsley Hospital on October 1, 1948 , his general nutrition was poor. There was swelling of both elbows, knees, proximal interphalangeal and metatarsal joints. Movement was limited at the elbows, which appeared to be painful. The muscles were greatly wasted in the vicinity of the affected joints. The E.S.R. was $12 \mathrm{~mm}$. in one minute and remained elevated during his stay in hospital. The pupils were dilated and reacted sluggishly to light, bút there was no other abnormality on routine neurological examination. No abnormality was detected in the cardiovascular, respiratory, or alimentary systems. He was a bed patient, and was doubly incontinent. He appeared to recognize only his mother. He did not speak except on one unconfirmed occasion with a night nurse. From time to time he screamed without apparent purpose and when in pain or not. He fingered toys aimlessly and would hold a book upside down. He made ineffective efforts to feed himself and would put toys, sheets, and paper in his mouth and chew and dribble.

An E.E.G. taken on October 11, 1948, was abnormal, though the record was incomplete. Very little alpha rhythm was seen and the dominant rhythms were irregular, with fairly low voltage $2-7 \mathrm{c}$./sec. activity. In the frontal and central regions short bursts of $20 \mathrm{c}$. $/ \mathrm{sec}$. were frequent and tended to become of fairly high voltage.

On October 26 convulsions began again and lasted for two and a half hours. They affected the right side more than the left, occasionally becoming generalized; the head and eyes turned rigidly to the right; the patient was cyanosed and his pupils were widely dilated.
On October 29 a note was made of periods characterized by sweating, dilated pupils, and tachycardia ; screaming remained his most troublesome symptom. There was no significant change in the E.E.G. on November 5 .

From November onwards the main therapeutic efforts were directed towards his physical rehabilitation. On February 16, 1949, he was able to walk the length of the ward and on March 8 to sit in the ward and show some interest in what was going on. On February 23 he suffered minor attacks, when he became flushed, halted in movement, and when eating dropped food from his mouth. Minor attacks of varied type continued to be noted up to five or six times daily. On May 12 fluttering of the eyelids, jerking of the limbs, and movement of the eyes to the right were observed. On May 19 there was noted spasm of the neck muscles, causing his head to drop on to his chest. There was a recurrence of status epilepticus on June 21 , lasting several hours. On July 7 involuntary twitching and jerking of the shoulders, arms, and hands began; this continued during the night.

Pyrexia had recurred on May 2, marking the onset of the final phase of the illness. On May 14 there was evidence of consolidation at both lung bases. On June 7 a high remittent fever began. Bed sores became extensive, oedema of the ankles and ascites developed, and he died on August 2.

\section{Post-mortem Investigation}

The body was grossly wasted. There were severe decubital ulcers on the hips and sacrum. On opening the skull, the dura mater, blood sinuses, and cerebral blood vessels were found normal. The cerebrospinal fluid was increased. The meninges, particularly over the base, were slightly fibrosed. The brain and spinal cord were preserved uncut in $10 \%$ formalin.

Both pleurae showed old adhesions and there were also some old adhesions of the pericardium to the heart. No fluid was found. The lungs were collapsed and airless except for the bases, which were congested on both sides. The heart, aorta, and coronary arteries were normal. The abdomen contained no fluid or adhesions. The liver appeared to be slightly fatty. The spleen was enlarged, soft, and septic. The kidneys, which were of normal size, showed no definite macroscopic changes. Death was thought to be due to toxaemia from decubital ulcers.

Histological investigation of the organs showed cloudy swelling of the liver, heart muscle, and kidney. There were no Aschoff nodules in the heart. The spleen was congested; the pancreas and several mesenteric and cervical lymph glands were normal. The pituitary and adrenal glands showed no change save for terminal congestion and post-mortem change. 


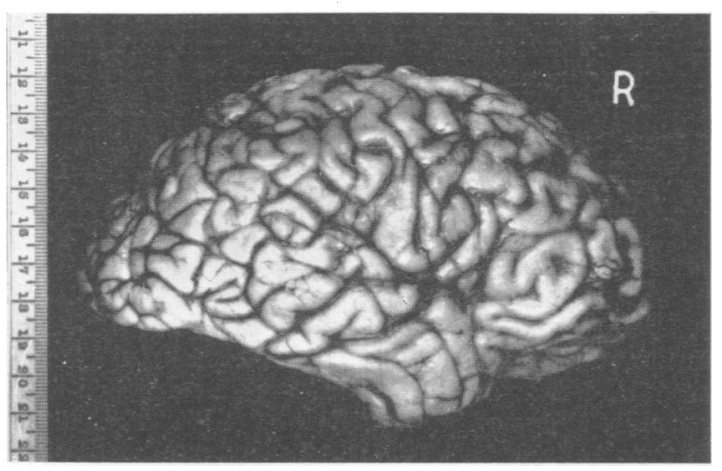

FIG. 1.-Lateral view of the right hemisphere.

Macroscopic Description of the Brain

The brain weighed $1,160 \mathrm{~g}$. No macroscopic abnormality was seen in the arteries at the base and convexity. The meninges generally were slightly thickened and opaque. There was definite symmetrical wasting of the convolutions (Figs. 1 and 2), most marked in the temporal lobes, which exhibited a peculiar shortened appearance, but almost equally marked in the frontal and particularly the medial orbital and anterior cingular regions. The parietal and occipital lobes and the posterior cingular region did not show any appreciable degree of atrophy.

Coronal dissection of the brain was still more informative. It showed, first, a considerable symmetrical enlargement of all ventricles including the inferior horn. Fig. 3 confirms the narrowness of the most medial orbital and the precallosal cingular convolutions; there was also varying atrophy of convolutions on the convexity. Fig. 4 brings out the narrowness of the cortex of the first temporal convolution as well as of the insula and the inferior frontal convolution. The amygdaloid nucleus is shown in Fig. 5 at its greatest extent and was found to be degenerated in its ventral parts. The corpus striatum was macroscopically intact, but the thalamus appeared abnormal and showed prominent blood vessels.

Fig. 6 presents a still more caudal coronal level of the temporal region. The superior temporal convolution is partially involved together with the insula and what is now supramarginal gyrus. Most of the remaining temporal convolutions are reduced in size, but the degeneration is most marked in the region around the collateral sulcus and in the hippocampal gyrus.

The localization of the lesions was almost identical in both hemispheres.

Coronal sections through more posterior levels of the parietal and occipital lobes did not reveal an appreciable degree of wasting.

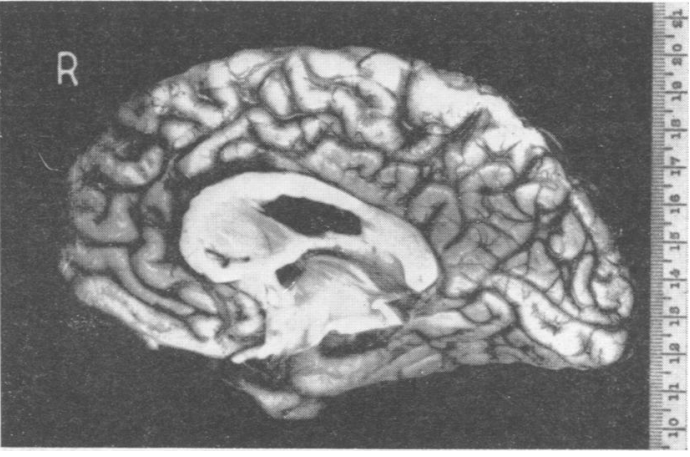

FIG. 2.-Medial view of the right hemisphere.

The hypothalamus and the brain-stem were free from macroscopic lesions. The cerebellum showed atrophy of several lobules, particularly near the central white matter.

\section{Histological Investigation}

This confirms the macroscopic observations. The meninges were slightly fibrous; neither here nor elsewhere in the brain were there any perivascular inflammatory infiltrations. The adventitia of most arteries and veins of large or medium size was fibrosed, but despite careful search no abnormality was seen in the media or in the intima.

Within the temporal lobe the width of the cortex, as compared with normal temporal lobes, was generally reduced. In addition there were areas of focal lesions. In the Sylvian region the cortex of the inferior frontal convolution, the insula, and the superior temporal convolution was grossly disorganized. Most nerve cells had disappeared. There was an overgrowth of macroglial and microglial cells together with newly formed capillaries (Fig. 7). Only a few compound granular cells were seen. Mallory preparations showed a considerable proliferation of the fibrous glia extending from the marginal layer into the third layer. There was also heavy gliosis in the capsula extrema and the claustrum which showed partial loss of nerve cells and shrinkage of the remaining ones. There was, however, even in this area of greatest destruction of the cortex, a considerable amount of lipoids in microglial and adventitial histiocytes and probably also in proliferating astrocytes.

Leaving this area of almost complete destruction of the cortex, the middle and inferior temporal convolutions showed fairly well preserved cellular architecture, but with increased marginal and upper layer gliosis. In the cortex surrounding the collateral sulcus there was in the depth of the sulcus a laminary loss of nerve cells in the third layer, with 


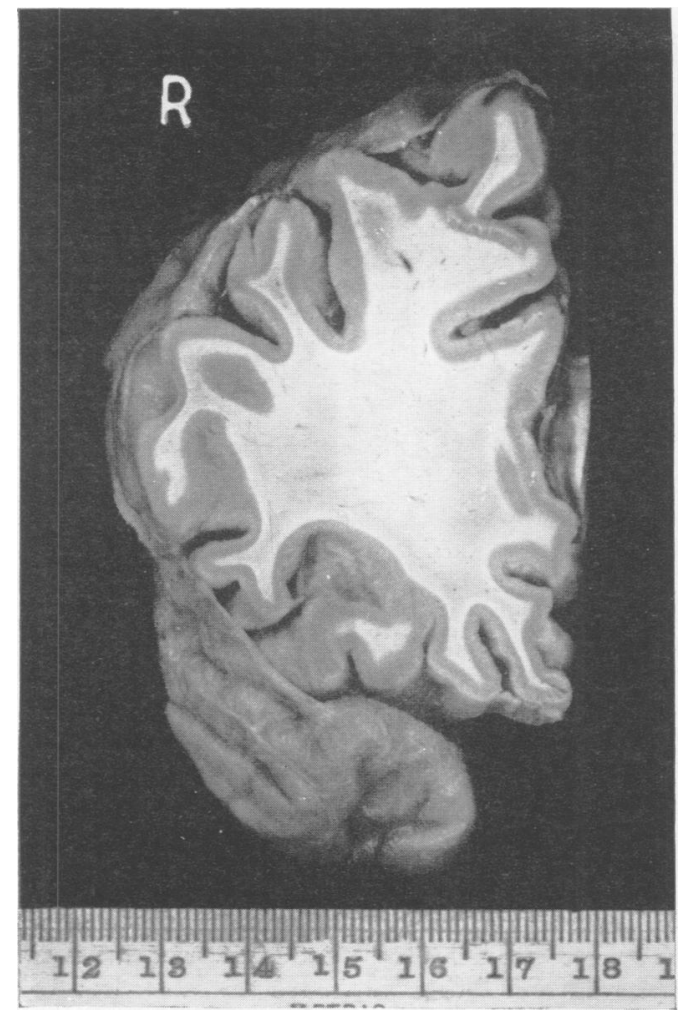

FIG. 3.-Coronal section through the anterior frontal region.

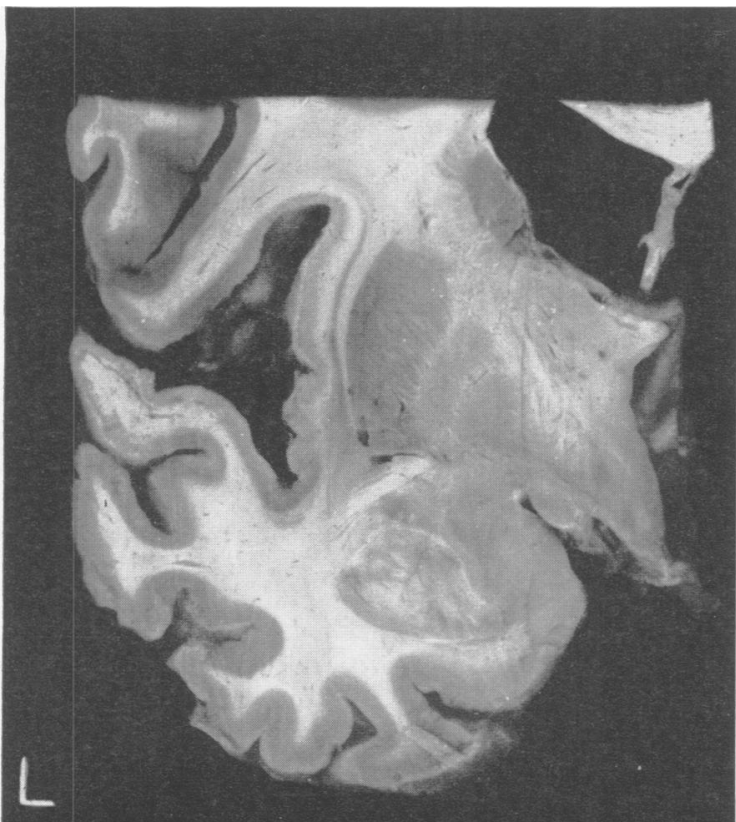

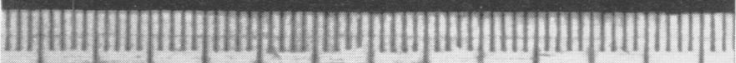

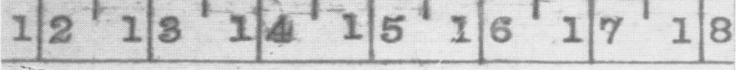

Fig. 5.-Coronal section through the greatest extent of the amygdaloid nucleus.

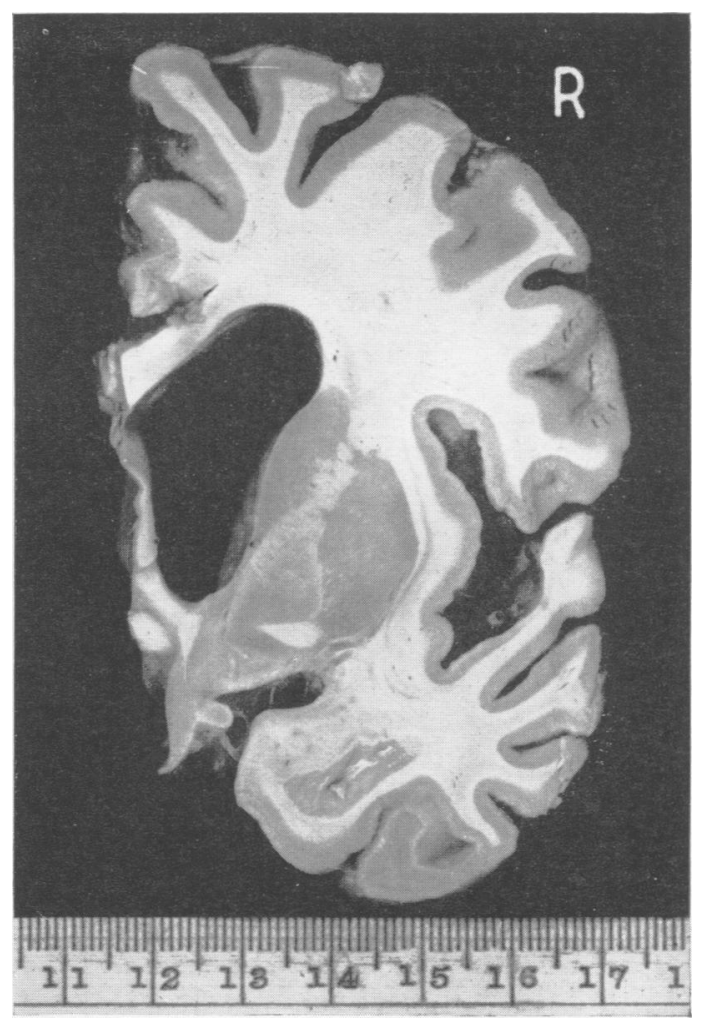

FIG. 4.-Coronal section at the level of the anterior commissure.

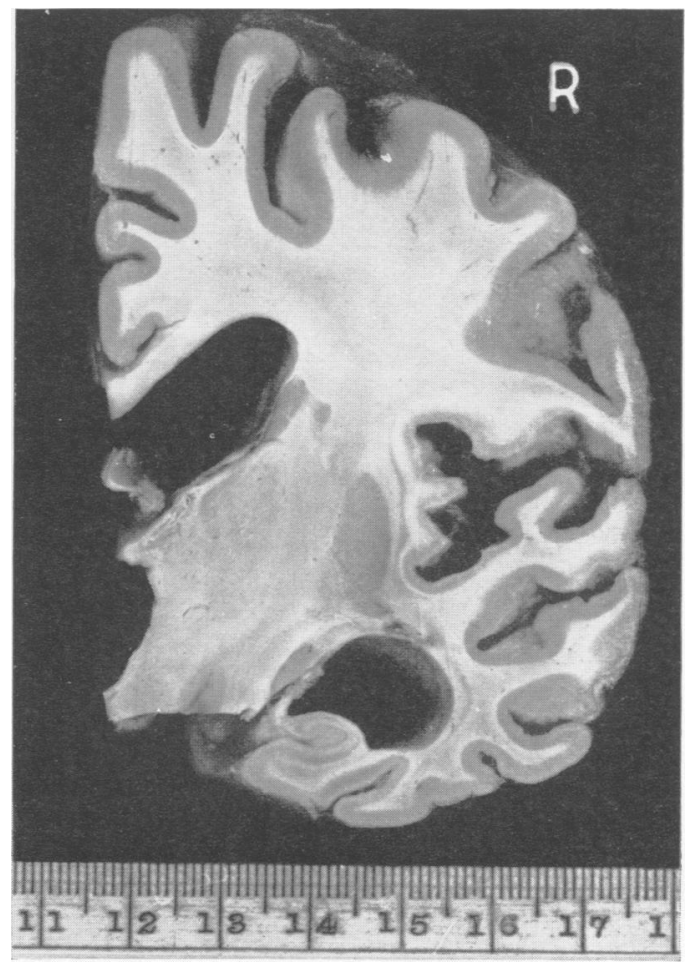

Fig. 6.-Coronal section at the level of Ammon's horn. 


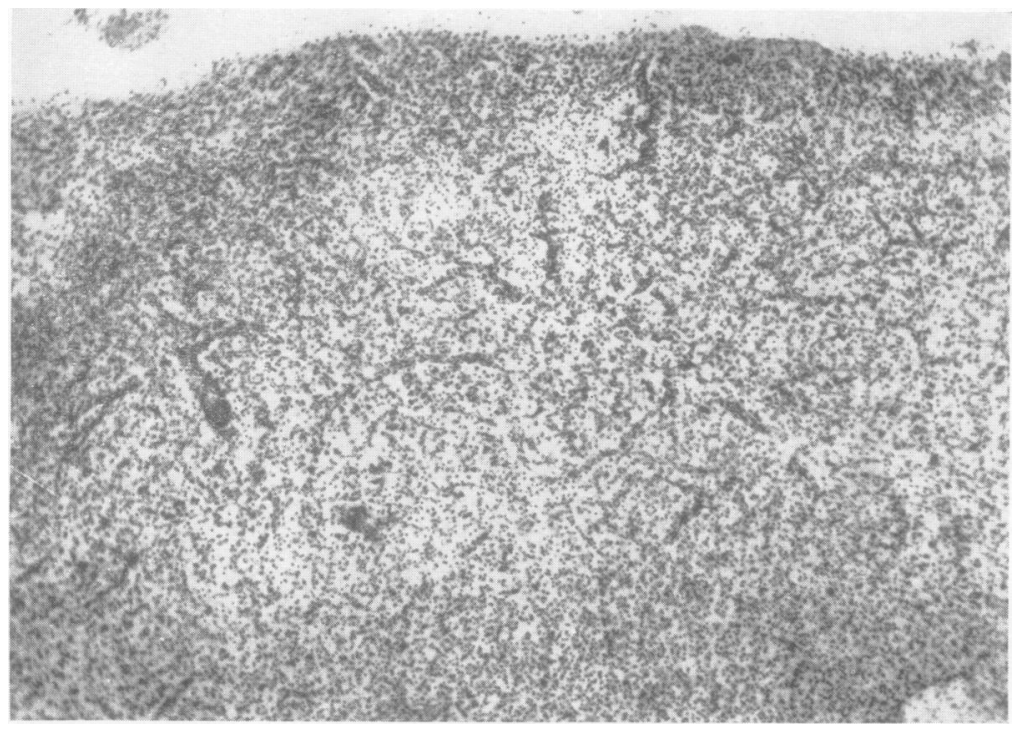

Fig. 7.-Insula cortex showing complete disorganization by loss of nerve cells and overgrowth of macro- and micro-glial cells and newly formed capillaries. Nissl stain. $\times 50$.

Fig. 8.-Laminary loss of nerve cells in the third layer of the cortex surrounding the collateral sulcus. Nissl stain. $\times 15$.
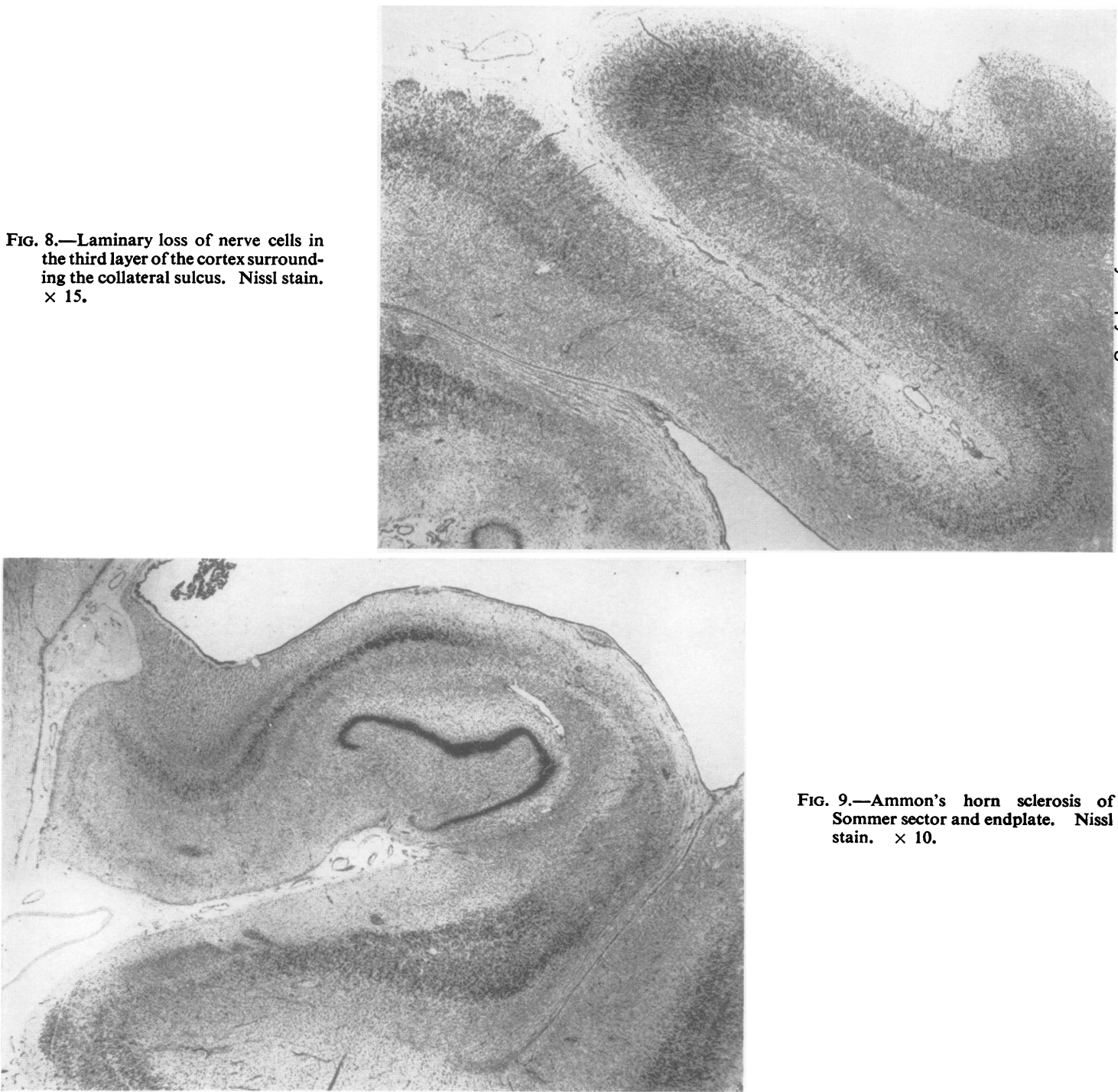

Fig. 9.-Ammon's horn sclerosis of Sommer sector and endplate. Nissl stain. $\times 10$ 
Fig. 10.-Ammon's horn ; considerable amount of lipoids in the Sommer sector mainly in microglial cells. Herxheimer's Scharlach $R$ stain. $\times 10$.
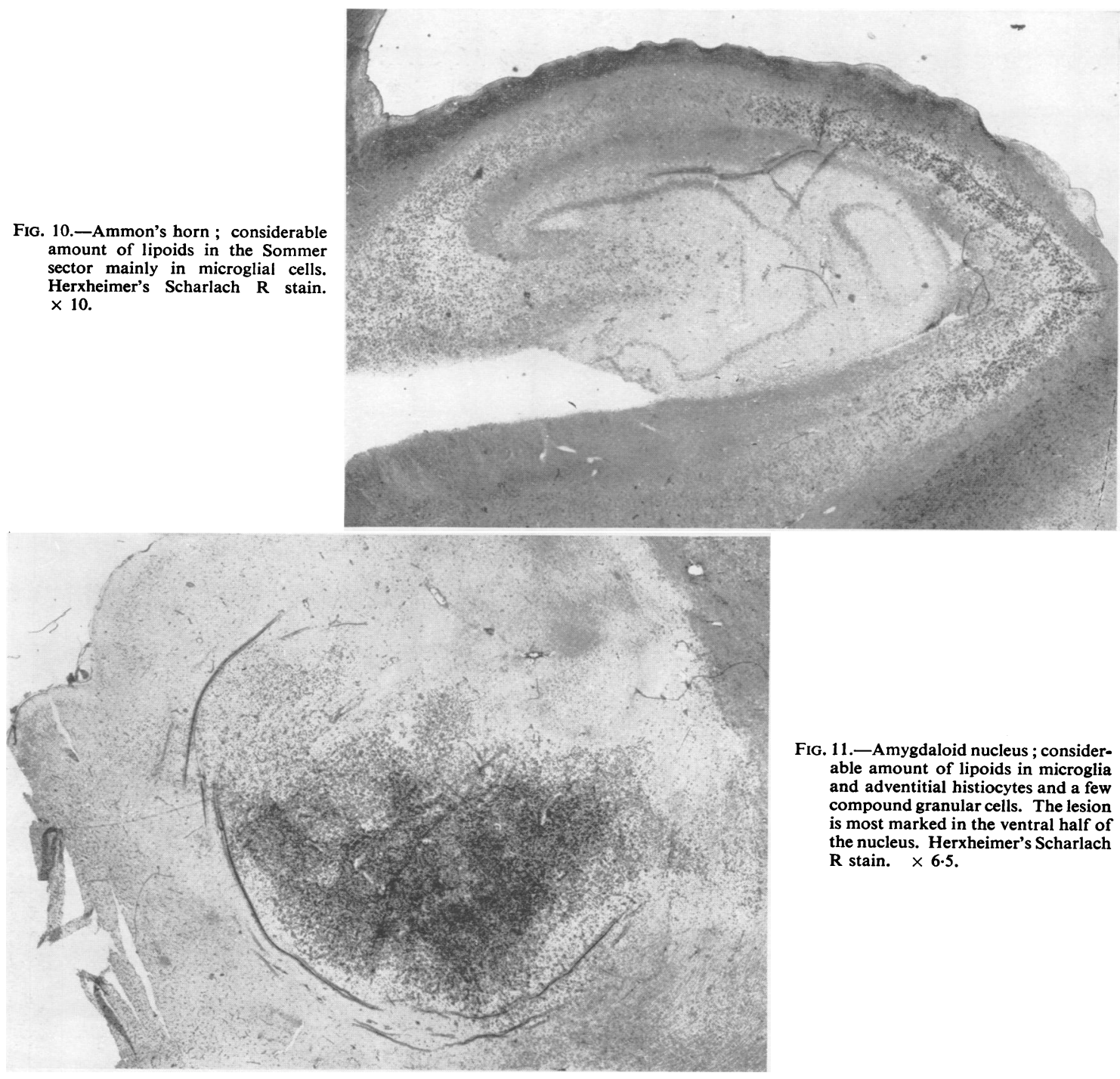

FIG. 11.-Amygdaloid nucleus ; considerable amount of lipoids in microglia and adventitial histiocytes and a few compound granular cells. The lesion is most marked in the ventral half of the nucleus. Herxheimer's Scharlach $R$ stain. $\times 6.5$.

Fig. 12.-Disseminated lobular sclerosis of cerebellar cortex. Nissl stain. $\times 2.5$.

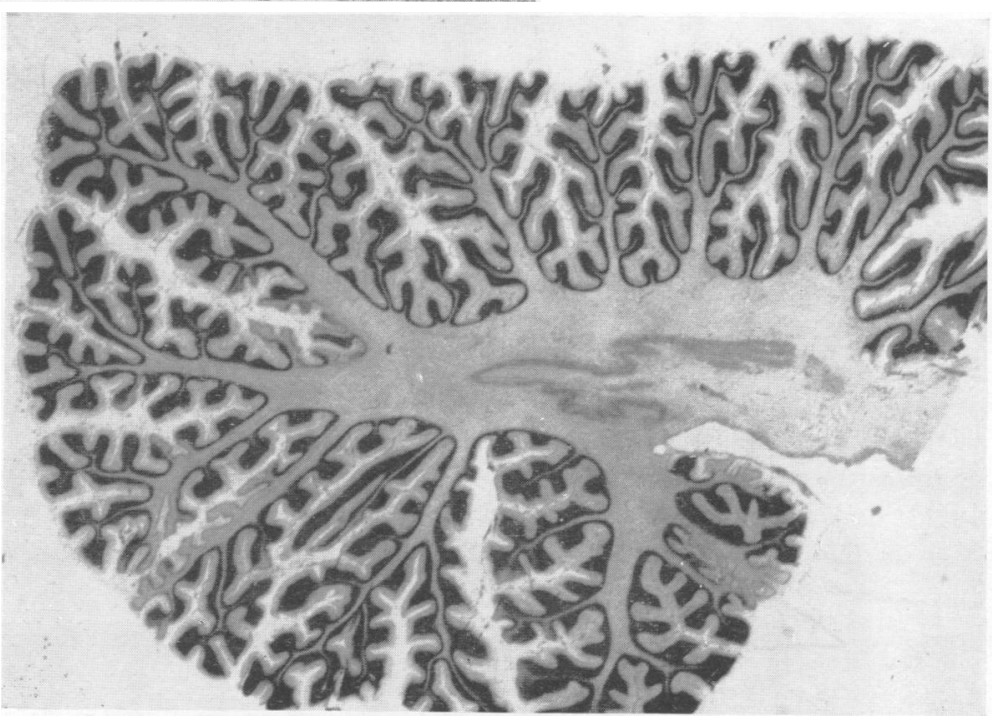


corresponding microglial and macroglial overgrowth (Fig. 8) and intensive marginal gliosis and gliosis of the white matter. Still more medially a typical sclerosis of the Sommer sector and endplate of the cornu Ammonis was seen (Fig. 9). Fat staining revealed much lipoid in microglial histio- dermal proliferation and lipoids in microglial cells, adventitial histiocytes, and in a few compound granular cells (Fig. 11).

Damage comparable to that in the Sylvian region was encountered in the mesial orbital and anterior cingular convolutions. There was extensive loss
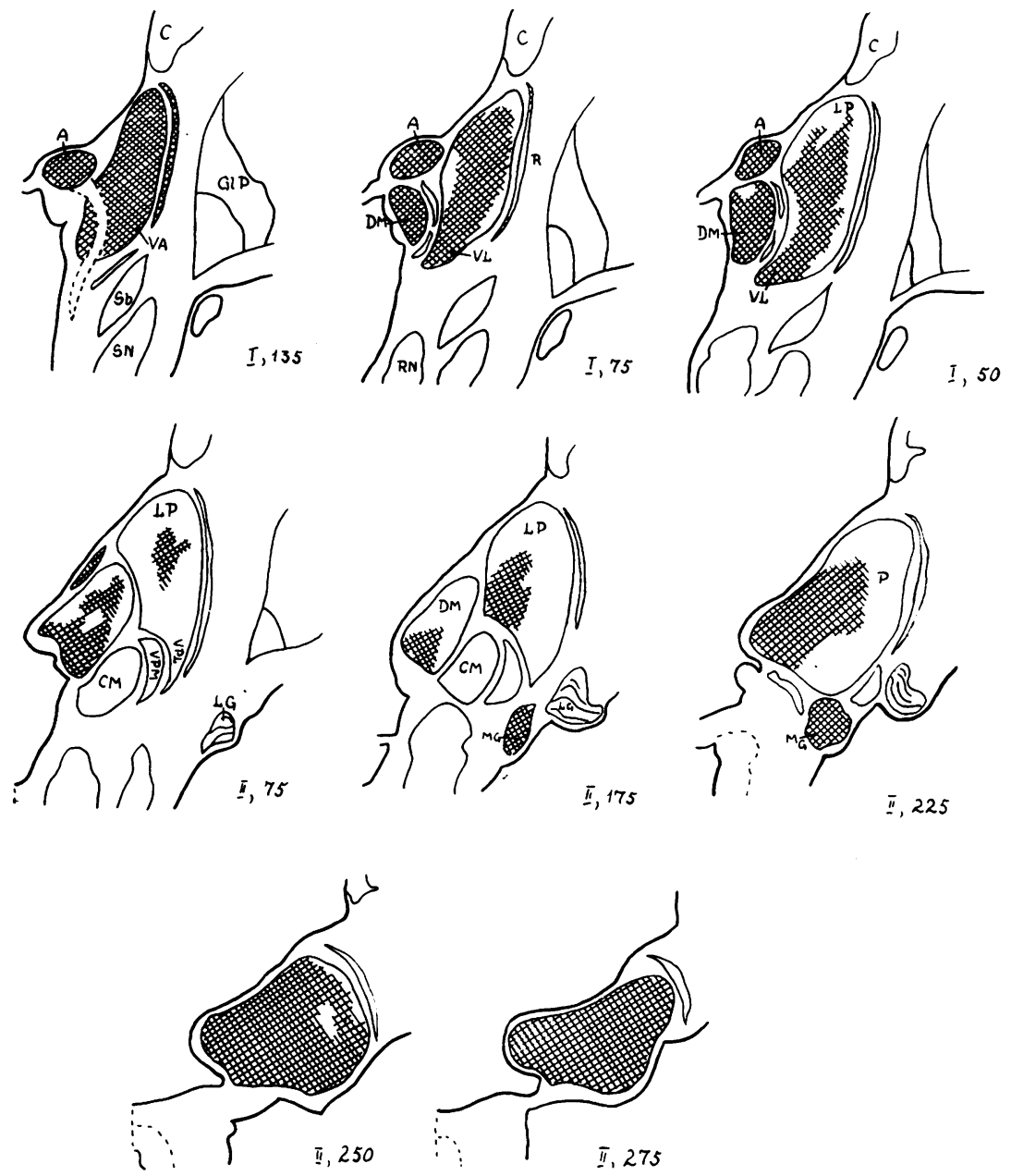

Fig. 13.-Diagram of retrograde degeneration in the right thalamus.

\footnotetext{
A : nucleus anterior thalami.

C : nucleus caudatus.

CM : nucleus centrum medianum.

DM : nucleus medialis dorsalis thalami.

GI P : globus pallidus.

LG : lateral geniculate.

LP : nucleus lateralis posterior thalami.

MG : medial geniculate.

P : Pulvinar.
}

cytes in the areas from which nerve cells had disappeared (Fig. 10). The lesion, which was identical on both sides, could be traced more anteriorly into the uncus. The amygdaloid nucleus in its ventral aspects showed extensive glio-meso-
$\mathbf{R}$ : nucleus reticularis thalami.

RN : nucleus ruber.

Sb : corpus subthalamicum.

SN : substantia nigra.

VA : nucleus ventralis anterior thalami.

VL: nucleus ventralis lateralis thalami.

VPL : nucleus ventralis postero-lateralis thalami.

VPM : nucleus ventralis postero-medialis thalami.

of neurons, particularly in the upper layers, with corresponding gliosis. The remaining frontal lobe showed similar changes, though of a lesser magnitude. Area 4 of Brodmann was narrower than normal, but the Betz cells were relatively spared. 
The rest of the hemispheres showed only mild changes, exemplified by the occipital lobe, which demonstrated histologically slight diffuse neuronal loss and increased marginal gliosis without appreciable disturbance of the cytoarchitecture.

While the corpus striatum showed no histological changes the thalamus was grossly abnormal, as Fig. 13 indicates. From this diagram it is seen that the anterior nuclear group, including the rostral part of the reticular nucleus, nuclei ventralis anterior and ventralis lateralis, had degenerated almost completely. Of the dorso-medial nucleus only the dorsal portion of its posterior part had escaped. Only a relatively small antero-lateral part of the pulvinar was preserved. It should be noted, however, that even in the most afflicted nuclei some scattered shrunken nerve cells could, with higher magnification, be detected among the much proliferated macroglial and oligodendroglial nuclei.

The nucleus lateralis posterior was little affected. The posterior ventral nuclei were intact. The lateral geniculate body stood out in its normality against the completely degenerated medial geniculate body.

Against this background of widespread degeneration the intralaminary nuclei, including the centralis lateralis, paracentralis, and centro-median, were conspicuous by their normality save for the centralis medialis, the greater part of which had been destroyed in the heavily gliosed massa intermedia, possibly due to primary vascular or anoxic disturbance or to the direct pressure effect of the hydrocephalus of the third ventricle.

Most of the midline nuclei including the paraventricularis anterior, reuniens, and rhomboid could be identified. They were normal except for their most medial parts, which were involved in a particularly heavy subependymal gliosis.

The analysis of the retrograde degeneration was made in the thalamus of the right hemisphere. The left thalamus appeared to exhibit similar changes, but their analysis was confined to sample levels.

The subthalamus and the hypothalamus were intact.

The midbrain and the rest of the brain-stem were preserved. There was no demyelination of the pyramidal tracts, but in Nissl sections there was a definite gliosis. The inferior olives were intact. The cerebellar cortex, however, particularly in the area near the central white matter, showed disseminated lobular atrophy (Fig. 12).

\section{Discussion}

Clinically, this was the case of a child whose first serious illness was that of Still's disease at the age of 9. During the course of treatment in hospital he suddenly and for no obvious reason went into status epilepticus ; this was followed by a three-day period of unconsciousness and then by a pneumonia; on recovery from the infection he was found to be severely demented. His mental state failed to improve during his remaining year of life, in the course of which minor, temporal lobe, and major seizures were observed. He died of toxaemia associated with decubital ulcers.

The pathological investigation has not entirely clarified the immediate cause of the first serial epileptic attacks. Towards the end of 1947 the patient showed the first symptoms of Still's syndrome. Earlier in that year he had also had rubella. Measles, mumps, and injections against pertussis were recorded in 1946. Against the arthritis he had been receiving blood transfusions, the last on June 5 , 1948 , that is, more than a month before the onset of the convulsions. The jaundice which developed in August, 1948, was attributed at the time to these transfusions. The application of plaster to the legs under rectal paraldehyde preceded the onset of status epilepticus by two days and was unremarkable. There would therefore seem to be no obvious nexus between the convulsions and any single preceding event in the medical history.

Whatever may have been the cause of the epilepsy, no sign of inflammatory reaction was found in the central nervous system. The arteries and veins, including the dural sinuses, were macroscopically normal, and histologically, despite careful search, no allergic or other abnormality could be detected in the blood-vessel walls, not even those minor changes which Meyer (1953) described as the sequelae of previous thrombosis. Thus this case is probably one more example confirming the often stated fact that particularly severe epileptic convulsions may be precipitated by childhood fevers, acute gastric infections, and allergic conditions in infancy and early childhood (Scholz, 1953 ; Meyer, 1953), although the exact pathogenic mechanism is not yet known. It is possible that the severe pneumonia which followed the status epilepticus may have been an important auxiliary pathogenic factor in the production of the lesions.

The lesions in the brain were clearly the consequence of circulatory disturbance or anoxia. They consisted of selective parenchymal degeneration (Scholz, 1949) in most areas, frequently confined to the third layer and to the depth of the sulcus. Only in areas of most severe affection, as, for example, had occurred in the convolutions surrounding the Sylvian fissure, was the whole of the cortex involved : the lesions resembled incomplete softenings. The 
Ammon's horn sclerosis and the disseminated cerebellar sclerosis were typical of lesions frequently found in brains of epileptics.

Particular attention has been paid to the age of the lesions. In all cortical necrotic areas there was still a considerable amount of lipoidal breakdown products within histiocytic elements which only rarely had progressed to the stage of granular compound cells. In our opinion none of the lesions could have been older than just over 12 months, i.e., than the first status epilepticus which had resulted in dementia. Some could have been of even more recent origin, probably caused by later recurrences of serial attacks.

The main interest of the case lies in the distribution of the lesions. In the first place, the emphasis is on the temporal lobe and the adjacent Sylvian region including the insula. This is of interest, since a proportion of the minor seizures which followed the generalized convulsions were of a type which would be described as temporal lobe seizures, particularly the screaming and flushing attacks. The electroencephalographic changes were, however, more severe and widespread than would be expected in temporal lobe epilepsy. This finding is in accordance with the wide distribution of pathological changes outside the temporal lobes. No special application of electrodes was practised at the time of the examination.

From Figs. 4 to 6 it is clear that the emphasis of the severity of lesions within the temporal lobe is on the first temporal convolution and the medial convolutions including the hippocampus, i.e., in the same areas which Earle, Baldwin, and Penfield (1953) regarded as particularly vulnerable during tentorial herniation and anoxia at birth. Their occurrence in our case demonstrates that this pathogenic mechanism is not exclusive for injury at birth but may occur in other conditions including status epilepticus itself. One of us (Meyer, 1939) has drawn attention to the importance of uncal pressure cone as an additional factor in the production of Ammon's horn sclerosis following epileptic seizures and has referred to a paper by Hasenjäger and Spatz (1937), who described the most characteristic uncal pressure cone of their series in a patient dying in status epilepticus.

Of the lesions in subcortical centres the one in the thalamus proved to be attributable mainly to retrograde degeneration. Its completeness, particularly in the anterior and anterior ventral nuclei, was surprising in view of the relatively well preserved posterior parts of the cingular gyrus and the widely expressed belief that the anterior ventral nucleus does not project on to the cortex. Perhaps this discrepancy may be resolved by the assumption that there may have been also some direct vascular damage to these nuclei in addition to the retrograde degeneration. Scholz (1951) has described vascular and anoxic lesions in the thalamus which occurred with particular frequency in the region of the anterior and lateral nuclei (vide his Fig. 26).

The fact that the system of intralaminary nuclei, including the centro-median nucleus, was almost entirely intact demonstrates that the greater part of the thalamic lesion must have been due to retrograde degeneration. Only the nucleus centralis medialis was found to be degenerated in the massa intermedia, which was probably directly damaged. It is idle to speculate in this case to what extent the thalamic reticular system was functionally involved in the mechanism of the minor and temporal lobe seizures, and, if so, which pathways would be available for impulses arising in this system. Impulses could hardly have been conveyed by the dorso-medial and anterior projection nuclei to the frontal region. The nucleus ventralis anterior and the rostral portion of the reticular nuclei which, according to Hanbery and Jasper (1953, 1954), collect and convey the impulses of the ascending reticular system, were also heavily damaged. Impulses could have been conveyed from the intact centro-median nucleus to the undamaged striate body (Droogleever-Fortuyn and Stefens, 1951), but their further passage to the frontal cortex through a largely degenerated thalamus would have been difficult. There would remain the possibility of circuitous pathways including an extra-thalamic pathway involving direct passage from the hypothalamic and subthalamic portion of the reticular system into the internal capsule (Starzl, Taylor, and Magoun, 1951). Although this discussion of the part played by the intralaminary system must remain inconclusive, it does demonstrate some of the unexpected difficulties of interpretation encountered in individual cases.

It was interesting to note that in the posterior plane of the dorso-medial nucleus the dorsal part was intact, thus confirming McLardy's (1950) finding that this part of the nucleus does not partake in the projection to the frontal lobe. The extensive retrograde degeneration of the pulvinar is explained by the considerable extent of the lesion in the temporal lobe, particularly in its caudal levels, as well as by that in the supramarginal gyrus. It is not possible to say whether the degeneration of the temporal pole had also contributed to the retrograde change in the pulvinar (Simpson, 1952). The fairly severe degeneration and gliosis of the claustrum which accompanied the softening of the insula had no retrograde effect upon the centro-median 
nucleus ; this observation should finally remove any lingering doubts concerning a projection of this nucleus to the claustrum (McLardy, 1948).

The softening in the ventral parts of the amygdaloid nucleus, which was bilateral, is illustrated in Figs. 5 and 11 , and is, so far as we can make out, the first observation of such a lesion in epileptic brains. Brockhaus (1939) described status marmoratus in the amygdaloid nucleus in two cases (Cases 4 and 5 of his series) of congenital and early infantile disease, but the relation to epilepsy was not clear. Since our attention has been drawn to the possibility of an amygdaloid lesion, we have been able to observe it as a post-epileptic phenomenon in several cases which include epilepsy from childhood and epilepsy caused by prefrontal leucotomy. In all but one the amygdaloid lesion was associated with severe sclerosis of Ammon's horn and the uncus.

A full account of these new findings will be given when the histological investigation in all cases is complete and the rate of incidence of amygdaloid lesions known. Until then there can be only reserved comment upon the possible repercussion of the observations in the amygdaloid nucleus upon the much-discussed and still intractable problem of the selective vulnerability and the functional significance of Ammon's horn.

Ammon's horn receives its vascular supply from the anterior choroidal artery, which also supplies the uncus, the amygdaloid nucleus, and the globus pallidus (Abbie, 1933 ; Alexander, 1942a and $b$ ). Interference with the blood supply confined to the more anterior branches which go to the hippocampus and amygdaloid nucleus would explain the necrosis of these centres, while the globus pallidus, which is supplied by posterior branches, remains unaffected. Uncal herniation as suggested by Penfield and his associates might commend itself as an event having such localized effect. It has been mentioned earlier in this discussion that uncal herniation, probably as a consequence of concomitant oedema, has been observed after death in status epilepticus.

Ammon's horn, the uncus, and the amygdaloid nucleus are also prominent members of the so-called visceral brain, which they form together with the anterior insula, posterior orbital and anterior cingular regions. Knowledge of the function of the visceral brain is still fragmentary and controversial, but if, as is now widely held, Ammon's horn and the amygdaloid nucleus play an active part in epileptic discharges in general, or at least in certain forms of epilepsy, then these centres would be, in a situation of general anoxia, more easily exhausted and succumb more readily to consumptive anoxia (Scholz, 1953). It is perhaps more than a coincidence that in our case all the regions of the visceral brain were severely damaged.

However, a full discussion of these intriguing aspects must wait until all the facts are marshalled.

\section{Summary}

The case has been described of a boy who at the age of 9 became ill with Still's syndrome. In the course of this illness he suddenly went into status epilepticus, which was followed by three days' coma and pneumonia. On recovery from the acute episode he was found to be demented. Subsequently he had grand mal, petit mal, and also what may be described as temporal lobe seizures. He died 12 months after the first epileptic seizure.

At necropsy he showed widespread damage in the brain due mainly to circulatory and anoxic disturbances associated with the first status epilepticus. The lesions were most severe in the first temporal convolution and adjacent Sylvian regions, Ammon's horn and the hippocampal gyrus, the medial orbital and the anterior cingular regions. The amygdaloid nucleus showed extensive incomplete softening.

The pathogenesis and functional significance of the lesions are discussed. Particular attention is drawn to the combination of lesions in the first temporal convolution and hippocampus, which Earle, Baldwin, and Penfield regarded as specific to herniation and anoxia at birth.

Special reference is made to the involvement of the amygdaloid nucleus.

We are indebted to Dr. K. Cameron, Physician to the Children's Department, for his permission to publish the case.

\section{REFERENCES}

Abbie, A. A. (1933). Brain, 56, 233.

Alexander, L. (1942a). In The Diseases of the Basal Ganglia. Nerv. Ment. Dis., Res. Publ. Ass., 21, 77. (1942b). Ibid., 21, 334.

Bateman, J. F. (1936). Arch. Neurol. Psychiat., Chicago, 36, 578. Brockhaus, H. (1939). J. Psychol. Neurol., Lpz., 49, 1.

Droogleever-Fortuyn, J., and Stefens, R. (1951). Electroenceph. clin. Neurophysiol., 3, 393.

Earle, K. M., Baldwin, M., and Penfield, W. (1953). Arch. Neurol. Psychiat., Chicago, 69, 27.

Hanbery, J., and Jasper, H. (1953). J. Neurophysiol., 16, 252. (1954). J. Neurosurg., 11, 24.

Hasenjäger, T., and Spatz, H. (1937). Arch. Psychiat. Nervenkr., 107,193 .

McLardy, T. (1948). Brain, 71, 290.

(1950). Journal of Neurology, Neurosurgery and Psychiatry, $13,198$.

Meyer, A. (1939). J. ment. Sci., 85, 927.

Falconer, M. A., and Beck, Elisabeth (1954). Journal of

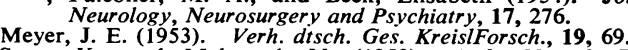

Sano, K., and Malamud, N. (1953). Arch. Neurol. Psychiat., Chicago, 70, 40.

Scholz, W. (1949). Arch. Psychiat. Nervenkr., 181, 621.

-(1951). Die Krampfschädigungen des Gehirns. Springer, BerlinGöttingen-Heidelberg.

Göttingen-Heidelberg.
(1953). Verh. dtsch. Ges. KreislForsch., 19, 52.

$\underset{\text { Simpson, D. A. (1952). J. Anat., Lond., 86, } 20 .}{ }$

Starzl, T. E., Taylor, C. W., and Magoun, H. W. (1951). J. Neurophysiol., 14, 461.

Stauder, K. H. (1935). Arch. Psychiat. Nervenkr., 104, 181. 